\title{
Life's a gas: saturation should not be used for prescription of long-term oxygen therapy
}

\author{
Magnus Ekström (1)
}

Faculty of Medicine, Dept of Clinical Sciences Lund, Respiratory Medicine and Allergology, Lund University, Lund, Sweden.

Corresponding author: Magnus Ekström (pmekstrom@gmail.com)

\begin{abstract}
Shareable abstract (@ERSpublications)
Transcutaneous oxygen saturation by pulse oximetry is unreliable for evaluating severe hypoxaemia or need for long-term oxygen therapy https://bit.ly/3CPZXOS
\end{abstract}

Cite this article as: Ekström M. Life's a gas: saturation should not be used for prescription of longterm oxygen therapy. ERJ Open Res 2021; 7: 00495-2021 [DOI: 10.1183/23120541.00495-2021].

Copyright $\odot$ The authors 2021

This version is distributed under the terms of the Creative Commons Attribution NonCommercial Licence 4.0. For commercial reproduction rights and permissions contact permissions@ersnet.org

Received: 5 Aug 2021 Accepted: 5 Aug 2021

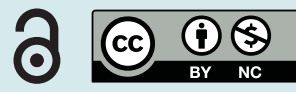

Hypoxaemia is a potential threat to all aerobic organisms, including humans. Long-term oxygen therapy (LTOT) given to people with chronic, severe hypoxaemia was the first intervention in COPD shown to prolong life [1, 2].

Eligibility for LTOT in the two landmark studies conducted in the 1970s was based on the arterial oxygen tension $\left(P_{\mathrm{aO}_{2}}\right)$ [1, 2]. Severe hypoxaemia was defined as a $P_{\mathrm{aO}_{2}}<7.4 \mathrm{kPa}$, or $<7.8 \mathrm{kPa}$ with signs of right-sided heart failure or secondary polycythaemia. These cut-points reflect a region on the oxygenhaemoglobin dissociation curve where even a small further decrease in $P_{\mathrm{aO}}$ is likely to cause a steep fall in arterial oxygen saturation $\left(S_{\mathrm{aO}_{2}}\right)$ measured by arterial blood gas (ABG) analysis.

Oxygen saturation measured using peripheral transcutaneous pulse oximetry $\left(S_{\mathrm{pO}_{2}}\right)$ is widely used as a proxy of $S_{\mathrm{aO}_{2}}$, especially for screening and monitoring of hypoxaemia. The practical advantages of pulse oximetry compared with obtaining ABGs are obvious. Thus, $S_{\mathrm{pO}_{2}}$ has been widely assessed, and the use has been broadened to even include the evaluation of hypoxaemia severity and need for LTOT in many settings, including the USA [3]. $S_{\mathrm{pO}_{2}}$ thresholds for identifying severe hypoxaemia and eligibility for LTOT are endorsed by major guidelines, such as the Global Initiative for Obstructive Lung Disease report [4], and recent LTOT guidelines from National Institute of Health and Care Excellence in the UK [5] and the American Thoracic Society [6]. $S_{\mathrm{pO}_{2}}$ was also used to assess eligibility in the large Long-Term Oxygen Treatment Trial, which failed to show any benefit from LTOT in patients with moderately reduced $S_{\mathrm{pO}_{2}}$ at rest or during exercise [7].

The problem is that $S_{\mathrm{pO}_{2}}$ is an inaccurate proxy of $S_{\mathrm{aO}_{2}} \cdot S_{\mathrm{pO}_{2}}$ varies considerably, with risk of both under- and overestimating the presence and severity of hypoxaemia and the need for LTOT, as compared with ABG values [8,9]. In contrast to what may be inferred from guidelines [4-6], a $S_{\mathrm{pO}_{2}}$ value cannot be reliably translated to a corresponding $P_{\mathrm{aO}_{2}}$ in an individual patient with severe respiratory disease.

In this issue of ERJ Open Research, LACASSE et al. [10] now add further data on the inadequacy of $S_{\mathrm{pO}_{2}}$ for evaluating severe hypoxaemia. In a secondary analysis of the International Nocturnal Oxygen trial, they firstly show that $S_{\mathrm{pO}_{2}}$ is only moderately correlated with $S_{\mathrm{aO}_{2}}$ (n=240 COPD patients). Next, they nicely illustrate significant variation between $S_{\mathrm{aO}}$ and $P_{\mathrm{aO}}$ values, as shown in figure 2 of their article. Patients with the same $P_{\mathrm{aO}_{2}}$ could have very different $S_{\mathrm{aO}_{2}}$, and the opposite was also true: that patients with the same saturation could have a wide range of values for $P_{\mathrm{aO}}$. This illustrates the fact that the oxygenhaemoglobin dissociation curve can differ markedly between people, depending on various factors as well as adaption to hypoxaemia, as discussed by the authors. Therefore, even if pulse oximetry is useful to monitor change in saturation over time, a value or range of $S_{\mathrm{pO}_{2}}$ cannot be directly translated into a corresponding value or range in $P_{\mathrm{aO}_{2}}$. 
Perhaps the most important finding by LACASSE et al. [10] is that defining severe hypoxaemia as $S_{\mathrm{aO}_{2}} \leqslant 88 \%$ would miss as many as $40 \%$ of patients with severe hypoxaemia on ABG ("false negative" $S_{\mathrm{aO}_{2}}$ ) and overdiagnose severe hypoxaemia in $2 \%$ ("false positive" $S_{\mathrm{pO}_{2}}$ ) of their study sample. Furthermore, when used to screen for hypoxaemia, the currently proposed cut-off of saturation $\leqslant 92 \%$ would miss $5 \%$ of patients who actually had severe hypoxaemia on ABG analysis and then would not qualify for blood gas assessment. In their study population, the threshold for identifying all cases of severe hypoxaemia on ABG analysis was a $S_{\mathrm{aO}_{2}} \leqslant 87 \%$ and the threshold for ruling out severe hypoxaemia was a $S_{\mathrm{aO}_{2}} \geqslant 96 \%$. The main limitation of the study is that predictive values could only be evaluated for $S_{\mathrm{aO}_{2}}$ (which requires ABG analysis) and not for $S_{\mathrm{pO}_{2}}$ (pulse oximetry), which would be used in clinics. However, as $S_{\mathrm{pO}_{2}}$ is only only moderately correlated with $S_{\mathrm{aO}_{2}}$, the accuracy of $S_{\mathrm{pO}_{2}}$ for identifying severe hypoxaemia is likely to be even worse.

Why are these findings important? The simple answer is that the evidence for LTOT to prolong survival is based on levels of $P_{\mathrm{aO}_{2}}[1,2]$. Use of $S_{\mathrm{pO}_{2}}$ to evaluate severe hypoxaemia or eligibility for LTOT is not evidence based and should be abandoned. Using current $S_{\mathrm{pO}_{2}}$ criteria could disqualify as many as $40 \%$ of patients who would meet the ABG criteria for LTOT: an intervention that can substantially prolong life. "False positive" prescription of LTOT using $S_{\mathrm{pO}_{2}}$ is less serious but can lead to unnecessary burden for patients and increased costs. Some may argue that $S_{\mathrm{aO}_{2}}$ might be more closely related to the blood's content and peripheral delivery of oxygen than $P_{\mathrm{aO}}$ and may be more closely linked to outcomes. This is an important area for research. However, as shown by LACASSE et al. [10], $S_{\mathrm{pO}_{2}}$ is still insufficiently correlated with $S_{\mathrm{aO}_{2}}$ for use in the individual patient. This is in line with an interesting recent analysis of $S_{\mathrm{pO}_{2}}$ versus $S_{\mathrm{aO}_{2}}$ (37308 paired samples from 178 intensive care units in the USA) [11]. Of patients in that study with $S_{\mathrm{pO}_{2}} 92-96 \%$, as many as $7.3 \%$ actually had a $S_{\mathrm{aO}_{2}}<88 \%$. Most importantly, the rate of "hidden desaturation" using $S_{\mathrm{pO}_{2}}$ was markedly higher in black patients (17.0\%) than in white patients (6.2\%) [11]. This bias in $S_{\mathrm{pO}_{2}}$ by skin colour needs to be acknowledged in research and clinical use.

Taken together, the data of LACASSE et al. [10] and previous findings have several clinical implications:

- LTOT should be prescribed based on $P_{\mathrm{aO}}$ and not $S_{\mathrm{pO}_{2}}$. The hypoxaemia should be established on several ABG analyses, optimally $\geqslant 3$ weeks apart to ascertain chronicity of the hypoxaemia despite optimal treatment for underlying conditions. Importantly, ABG analysis also provides information on the presence and severity of alveolar hypoventilation, carbon dioxide retention, and the patient's acidbase status, which is important for LTOT titration.

- Severity of arterial hypoxaemia and saturation should be confirmed by ABG analysis, especially in patients with severe illness and to guide management.

- The widely recommended screening threshold of $S_{\mathrm{pO}_{2}} \leqslant 92 \%$ to perform ABG analysis assessment should be further investigated and potentially revised.

- Major treatment guidelines should be amended accordingly to reflect the current evidence base for evaluating severity of hypoxaemia and need for LTOT.

As pointed out by Marc Boland in his 1971 song, unknowingly commenting on the role of $S_{\mathrm{pO}_{2}}$ in LTOT prescription, “It really doesn’t matter at all, life’s a gas”.

Provenance: Commissioned article, peer reviewed.

Conflict of interest: None declared.

Support statement: M. Ekström was supported by an unrestricted grant from the Swedish Research Council (Dnr: 2019-02081). Funding information for this article has been deposited with the Crossref Funder Registry.

\section{References}

1 Nocturnal Oxygen Therapy Trial Group. Continuous or nocturnal oxygen therapy in hypoxemic chronic obstructive lung disease: a clinical trial. Ann Intern Med 1980; 93: 391-398.

2 Medical Research Council Working Party. Long term domiciliary oxygen therapy in chronic hypoxic cor pulmonale complicating chronic bronchitis and emphysema. Lancet 1981; 1: 681-686.

3 US centers for medicare and medicaid services. Medicare learning network. Home Oxygen Therapy. https:// www.cms.gov/Research-Statistics-Data-and-Systems/Computer-Data-and-Systems/Electronic-Clinical-Templates/ DMEPOS-Templates/DMEPOS-Home-Oxygen-Therapy Date last assessed: 5 August 2021.

4 Global Initiative for Chronic Obstructive Lung Disease. Global Strategy for the Diagnosis, Management and Prevention of COPD, 2021. Available from: http://goldcopd.org/ Date last accessed 29 July 2021.

5 Hardinge M, Annandale J, Bourne S, et al. British Thoracic Society guidelines for home oxygen use in adults. Thorax 2015; 70: Suppl. 1, i1-i43. 
Jacobs SS, Krishnan JA, Lederer DJ, et al. Home oxygen therapy for adults with chronic lung disease. An official American Thoracic Society clinical practice guideline. Am J Respir Crit Care Med 2020; 202: e121-e141.

7 The Long-Term Oxygen Treatment Trial Research Group. A randomised trial of long-term oxygen for COPD with moderate desaturation. N Engl J Med 2016; 375: 1617-1627.

8 Carlin BW, Clausen JL, Ries AL. The use of cutaneous oximetry in the prescription of long-term oxygen therapy. Chest 1988; 94: 239-241.

9 Roberts CM, Bugler JR, Melchor R, et al. Value of pulse oximetry in screening for long-term oxygen therapy requirement. Eur Respir J 1993; 6: 559-562.

10 Lacasse $\mathrm{Y}$, Thériault S, St-Pierre B, et al. Oximetry neither to prescribe long-term oxygen therapy nor to screen for severe hypoxaemia. ERJ Open Res 2021; 7: 00272-2021.

11 Sjoding MW, Dickson RP, Iwashyna TJ, et al. Racial bias in pulse oximetry measurement. N Engl J Med 2020; 383: $2477-2478$. 